\title{
Reconhecer as diferenças para superar os (pre)conceitos de gênero e de sexualidade na educação
}

\author{
Gênero, educação e sexualidade: reconhecendo diferenças \\ para superar (pre)conceitos. \\ BUENO, André da Silva; ESTACHESKI, Dulceli Tonet; CREMA, Everton Carlos \\ (Orgs.).
}

Uberlândia: Ed. dos Autores, 2016.

\begin{abstract}
O prefácio do livro Gênero, educação e sexualidade: reconhecendo diferenças para superar (pre)conceitos, escrito por Carla Satler, inicia com uma citação de Michel Foucault sobre revolucionar a si para, então, revolucionar de fato alguma coisa. Essa ideia sintetiza a proposta do livro no sentido de mudar horizontes particulares para afetar revoluções coletivas. A partir disso, a igualdade sobre gênero, educação e sexualidade torna-se possível de alcançar, primeiramente, se forem reconhecidas as diferenças sociais a fim de superar os (pre)conceitos. Também, apresenta-se a história que permeia a concepção do livro e do grupo de pesquisadores/as e militantes pela igualdade de gênero, que exercem uma empatia social capaz de reinterpretar o mundo e promover pontes de saberes entre a universidade e o cotidiano escolar da comunidade.

Segundo a autora do prefácio, a ideia de gênero contida no livro é uma ousadia dos/ as profissionais que o escrevem diante do atual momento político do Brasil, em que se enfrenta um embate religioso fundamentalista contra os estudos de gênero nas câmaras legislativas, o que disseminou o termo pejorativo 'ideologia de gênero'. Nesse sentido, ousar é desafiar a ordem de um Estado que não preza por ser laico ou por ter representatividade social, nem reconhece a diversidade de gênero. Tal audácia acontece pela urgência de sair do senso comum discriminativo, uma reação contra leis de poderes arbitrários sobre a irrelevância de estudar gênero em nossa sociedade. Por isso, a resistência deve ser contínua, conforme Carla Satler (2016, p. 08), com o "objetivo de romper os paradigmas de uma cultura machista, homotransfóbica e preconceituosa sedimentada no espaço escolar. Tarefa difícil que exigiu coragem, desprendimento e delicadeza".

Na apresentação de Dulceli Estacheski é citado o projeto 'Gênero e diversidade sexual: ações afirmativas para combater a violência' pensado por ela e seus colegas André Bueno
\end{abstract}


e Everton Crema da Universidade Estadual do Paraná, campus de União da Vitória. O projeto aprovado em 2014 no Programa Universidade sem Fronteiras da Secretaria de Estado de Ciência, Tecnologia e Ensino Superior do Paraná, conseguiu recursos para ter bolsistas e ampliar os trabalhos em 2015 com disciplina optativa no Curso de graduação em História, realização de palestras e de oficinas em escolas, além de participação em eventos acadêmicos e em espaços midiáticos. Essas iniciativas dedicadas aos estudos de gênero modificam a realidade de conservadorismo interiorano, espelho de toda cultura machista e heteronormativa na qual historicamente somos educados(as). Nessas ações incansáveis Dulceli Estacheski (2016, p. 12) cita a dignidade humana que deve ser experimentada por todas as pessoas "para que os preconceitos sejam rompidos e para que a sociedade atue de fato no combate à violência de gênero".

O capítulo "Gênero, sexo, sexualidades: categorias do debate contemporâneo", de Cristina Wolff e Rafael Saldanha, apresenta alguns resultados do trabalho realizado pelo Instituto de Estudos de Gênero da UFSC, com o Curso de Especialização em "Gênero e Diversidade na Escola", apoiado pela SECADI/MEC. A partir disso, são abordadas categorias fundamentais a fim de discutir sobre dúvidas levantadas por alunas do curso, que são professoras na Educação Básica, sobre os conceitos sexo, gênero e sexualidade. O sexo refere-se às características biológicas dos corpos classificadas em machos/homens e fêmeas/mulheres, além de intersex ou hermafroditas. O gênero relaciona-se às relações de poder, conforme Joan Scott (1990, p. 86), "é um elemento constitutivo de relações sociais fundadas sobre as diferenças percebidas entre os sexos e o gênero é um primeiro modo de dar significado às relações de poder", diferenciando, assim, pessoas em femininas ou masculinas e cisgêneros, transgêneros ou não binárias, algo que se relaciona à "expressão", ao "papel" sexual ou à performance. A sexualidade ou orientação sexual é associada às práticas afetivas e sexuais das pessoas, sejam heterossexuais, homossexuais, bissexuais, omni/pansexuais e assexuais. Assim, destaca-se a não obviedade desse contexto, em que se rompe expectativas "heteronormativas" e possibilita enxergar a diversidade e a desconstrução de estereótipos de gênero discriminativos.

Em "Feminismo, sexo e gênero" são abordados por Wolff e Saldanha os estudos de um novo sujeito social: "a mulher" ou "o segundo sexo", algo ainda mais visível a partir de 1949 no Brasil com a publicação do livro de Simone de Beauvoir. Ainda, são lembradas as mulheres precursoras na luta por seus direitos desde o século XVIII, o que promoveu mais força na segunda metade do século XIX com o movimento social do feminismo que reivindicava o voto para mulheres. Nessa primeira onda do feminismo, o sufragismo, tornouse importante mostrar a participação feminina na história, na cultura, nas artes e na economia, assim como fizeram as escritoras brasileiras Nísia Floresta (1810-1885) e Maria Lacerda de Moura (1887-1945). Além do voto, as mulheres reivindicavam o direito à educação e, com a segunda onda do feminismo, de acordo com Joana Maria Pedro (2012), novas reivindicações emergiram com palavras de ordem até hoje necessárias: "salário igual para trabalho igual", devido ao salário inferior que as mulheres recebem para exercer uma mesma função que os homens; "o privado é político" em razão da violência doméstica, dos direitos reprodutivos e dos cuidados com as crianças e tarefas domésticas para serem tratadas como questões de políticas públicas do Estado; e o "nosso corpo nos pertence" referente à autonomia das mulheres com o próprio corpo, o direito reprodutivo de serem mães ou não, o direito ao prazer sexual e a liberdade de vestirem e se portarem como desejavam.

Na seção "Sexo, mulher, mulheres", Wolff e Saldanha abordam as diferenças sociais entre mulheres e homens, as quais envolvem desconstrução de paradigmas sexistas como a subordinação das mulheres aos homens e as diferenças naturalizadas através do sexo. 
Em "Gênero" os autores apresentam o tema como inerentes às relações sociais, igualmente a classe, raça, geração e outras categorias. Na parte "Campo da sexualidade", os autores apontam suas aulas no curso de especialização para professoras Gênero e Diversidade na Escola, que promoveram questionamentos ao discutir a presença de alunos(as) com diferentes orientações sexuais e identificações de gênero, assim como bullying e violências de gênero entre adolescentes. Na sessão "Sexo: três partes do mesmo corpo" os autores analisam três noções básicas: sexo biológico, sexo cultural e ato sexual, todos íntimos da corporeidade humana e de marcas identitárias, não necessariamente associadas entre si. Retomando o pensamento de Guacira Louro (2000), no senso comum, espera-se que as marcas de sexo, gênero e sexualidade indiquem - sem ambiguidade - as identidades de quem as possui, o que revela a necessidade social limitante de enquadrar alguém (ou a nós mesmos/as) em uma identidade pré-definida e familiar. Por isso, o diferente deve ser respeitado e valorizado sobrepondo qualquer preconceito.

Everton Carlos Crema, no capítulo "Rüsen e o 'novo humanismo' reflexões para a educação e a diferença", dedica-se ao ensino da história e um 'humanismo histórico', que abrange a identidade e a diferença como essenciais na organização política da vida social. Supera-se, com isso, o racionalismo lógico universal através do 'humanismo diverso', que soma a diversidade cultural e as individualidades como base de um novo e necessário humanismo. Ainda, o pesquisador menciona o cuidado para não tornar a relativização histórica um modelo de 'racionalização' simplista, pois deve permitir às pessoas o sentido crítico e a valorização da alteridade como um pensamento humanista histórico. A empatia social, nesse exercício, percebe as diferenças e torna o conhecimento histórico uma ferramenta de entendimento e aproximação, não de exclusão, principalmente no tocante às reações à diversidade de gênero, estigmatizada por uma heteronormatividade que, muitas vezes, é anacrônica e eterniza o passado no presente, nega o devir histórico e reforça problemas como a subversão da história e a ausência de crítica positiva e valorativa.

No capítulo "Gênero na escola sim, mas como fazer?" Dulceli Estacheski trata sobre as dificuldades de entender gênero fora da academia, principalmente no ambiente escolar e oferece caminhos para abordar o tema didaticamente entre alunos(as). A autora retoma Joan Scott (1995, p. 91), referência nos estudos de gênero e seu artigo "Gênero: uma categoria útil de análise histórica", no qual define gênero como "um primeiro modo de dar significado às relações de poder". Posteriormente, Scott percebeu que a discussão de gênero ainda se fazia extremamente necessária quando foi lançado, em 2011 na França, um material didático aprovado pelo Ministério da Educação que incluía o tema de biologia humana 'Tornar-se homem ou mulher', o qual foi considerado por políitcos, religiosos, pais e alguns educadores como censurável. Esse fato mobilizou campanhas midiáticas massivas contra o manual, o qual foi chamado de 'ideologia de gênero'. O Ministro da Educação na época não retirou o manual de circulação, mas, desde então, Scott (2012, p. 331) afirma que: "em vez de (como eu equivocadamente pensei) tornar-se mais claro ao longo do tempo, gênero se tornou mais impreciso; o lugar de contestação, um conceito disputado na arena política".

Essa realidade comprovou a necessidade das reflexões sobre mulheres, desigualdade e diferença sexual, algo que aconteceu também no Brasil em 2015 em relação aos Planos Municipais e Estaduais de Educação. Nesse contexto, despertou-se um interesse das famílias nunca visto antes, infelizmente, não sobre o conteúdo dos programas escolares, mas sobre a supressão do termo gênero nos planos de educação. A decisão incomodou lideranças religiosas que distorceram a temática, apavorando pais, mães e demais tutores(as) de crianças, as quais respeitaram os discursos religiosos e desconsideraram diálogos com a escola. 
Nesses episódios, analisa-se a violência na fala combativa ao tema gênero e ao tentar calar quem promove tal educação. Nisso, retoma Rüsen sobre a diversidade cultural, no que se refere à experiência entre estudantes, a qual é capaz de motivar a proximidade e o respeito entre as diferenças em todos os ambientes vivências sociais. Humanidade essa que nos condiciona pela capacidade de olhar e valorizar a outra pessoa. Então, a autora questiona qual ser humano poderia ser destruído ao debater gênero e, com isso, exemplifica a humanidade que exclui a diversidade e considera como família apenas a que segue o próprio padrão de fé religiosa. Isso se deve às acusações sobre os debates de gênero destruírem a família e o ser humano, enquanto que a violência maior é excluir e ignorar a diversidade humana, assim como quem posicionou-se contra gênero no plano escolar.

Dulceli Estacheski ainda apresenta pesquisas que se dedicam às dúvidas de professores/as principalmente à conceituação de gênero, em que aparece muito a equiparação de gênero e sexo (feminino e masculino), bem como a ideia de que os estudos de gênero tratam apenas de mulheres e homossexuais. Tais inquietações precisam de atenção para que a formação discente - e também a docente - abranja conhecimento sobre gênero e diversidade sexual. Ainda, muitos(as) professores(as), ao serem questionados/ as sobre quando a escola deve debater gênero, afirmaram ser importante debater quando surgirem situações que envolvam o tema. Esse procedimento desvela outro problema, pois arrisca-se não saber agir diante da situação e tratar como problema - o que não é - devido ao desconhecimento, o que dificulta a ação.

Sobre isso, pode haver o entendimento de perceber o sujeito como o problema e não o preconceito ou a discriminação em relação a ele, práticas que devem ser o centro do combate em prol de uma educação que incentive respeito entre as diferenças. Assim, percebe-se o perigo de ter docentes e discentes desinformados/as sobre gênero, pois a escola torna-se excludente quando nega conhecimento e perpetua violências contidas em estereótipos. Por isso, a escola deve buscar se aproximar das minorias sociais que mais são afetadas, para combater discriminações, assim como mulheres, LGBTs, negros(as) e indígenas, grupos que devem ser ouvidos pois, conforme Dulceli Estacheski (2016, p. 77): "a escola, assim como a academia, precisa deixar falar e precisa aprender a ouvir. Isso nos ajudaria a compreender que podemos falar com, ao invés de apenas falar de". Para a autora isso contribui para tornar uma preocupação de todas as pessoas o fim de preconceitos e violências de gênero, de classe e de raça/etnia, entre outras, aprendendo sobre dignidade humana.

A relevância de ações educativas de gênero nas escolas também é tradada no capítulo de Sergio Andrigueto e, para isso, são necessários materiais de apoio e projetos práticos que desconstruam, como sugere o capítulo de Vanessa Chucailo, "Impressões sobre identidades de gênero: o desafio dos modelos ideais", e fomentem novas percepções. Exemplo disso é o capítulo de Ana Paula Bührer Gonçalves sobre o projeto de extensão "Gênero e Diversidade Sexual: ações afirmativas para combater a violência", o qual promoveu na escola onde o projeto foi realizado um ensino igualitário e inclusivo. Além disso, o capítulo de Elaine Schmitt e Karina Janz Woitowicz apresenta referências educativas como a animação Hora da Aventura sobre sexualidade desromantizada, propondo novas abordagens de gênero na programação infantil. Complementando isso, os capítulos "História das mulheres: o que ler?", de André Bueno, e "Revista Realidade: as mulheres diante do sexo uma década quebrando tabus", de Thays Bieberbac, elucidam caminhos bibliográficos que se somam ao embasamento dos estudos de gênero. No último capítulo realizado por Ana Paula Bührer, Dulceli Estacheski, Everton Crema, Sergio Andrigueto e Vanessa Chucailo, "Sugestões para pesquisas e reflexões sobre gênero" são oferecidas referências de filmes, séries, documentários e animações, os quais formam um material 
pertinente para complementar os temas de gênero, sexualidade e educação abordados no livro.

Assim, as contribuições dessa obra formam um guia atual sobre gênero, sexualidade e educação, em que são apresentados conceitos e práticas fundamentais para a abordagem de tais temas. Dessa forma, os autores e as autoras elaboram caminhos para superar preconceitos e a discriminação de gênero que, muitas vezes, acontecem de modo violento e excludente, como são apontadas em algumas práticas docentes nos capítulos, que mostram a importância de preparar professores/as para reconhecer a diversidade de gênero no ambiente de ensino e, assim, ter condições democráticas e inclusivas para debater $o$ assunto e combater as desigualdades. Esse processo mostra-se complexo diante da resistência de muitos grupos conservadores sobre o termo gênero nos planos de ensino, conforme a leitura do livro, entre outras questões culturais sexistas e heterocentradas, as quais dificultam a prática de educacional em defesa da diversidade de gênero. Apesar disso, a construção deste livro demonstra o engajamento político que permite em diversas instâncias a transformação necessária nesse cenário social, para fomentar um maior reconhecimento sobre a diversidade de gênero e de sexualidade na educação, de forma didática e interdisciplinar para garantir os direitos e a dignidade humana.

\section{Referências}

BUENO, André da Silva; ESTACHESKI, Dulceli Tonet; CREMA, Everton Carlos (Orgs.). Gênero, educação e sexualidade: reconhecendo diferenças para superar (pre)conceitos. Uberlândia: Ed. dos Autores, 2016.

LOURO, Guacira Lopes. "Corpo, escola e identidade". Educação \& Realidade. Porto Alegre, V. 25, n. 2 , p. $59-75,2000$.

PEDRO, Joana Maria. "Corpo, prazer e trabalho". In: PINSKY, Carla Bassanezi; PEDRO, Joana Maria. Nova história das mulheres no Brasil. São Paulo: Contexto, 2012, p. 238-259.

SCOTT, Joan Wallach. "Gênero: uma categoria útil de análise histórica". Educação \& Realidade. Porto Alegre, v. 16, n. 2, p. 5-22, jul/dez., 1990.

"Gênero: uma categoria útil de análise histórica". Educação \& Realidade. Porto Alegre, vol. 20, n. 2, p. 71-99, jul./dez. 1995.

. "Os usos e abusos do gênero." Projeto História, São Paulo, n. 45, p. 327-351, dez. 2012.

[Recebida em 27/09/2017

e aceita em 20/02/2018]

Luana Borges Lemes'

'Universidade Federal de Santa Catarina, Programa de Pós-Graduação em História, Florianópolis, SC, Brasil

Luana Borges Lemes (lu borges@hotmail.com) é mestranda no Programa de PósGraduação em História da Universidade Federal de Santa Catarina. Vinculada à linha de pesquisa Subjetividades e relações de poder, dedica-se à área de gênero e feminismos pesquisando maternidade, maternagem, gênero, feminismo e história oral. Foi integrante do Laboratório de Estudos de Gênero (LEGH) da mesma instituição.

ib) 0000-0002-1825-0097 